Modelling of Corroding Concrete Structures 


\section{RILEM BOOKSERIES}

Volume 5

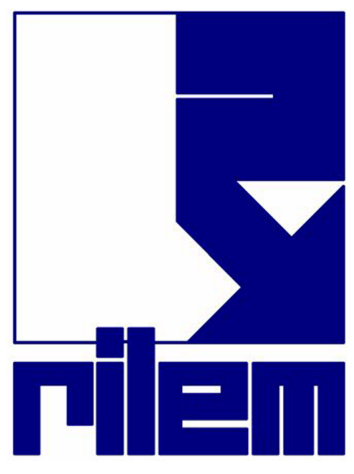

For other titles published in this series, go to www.springer.com/series/8781 
Carmen Andrade • Giuseppe Mancini

Editors

\section{Modelling of Corroding Concrete Structures}

Proceedings of the Joint fib-RILEM Workshop held in Madrid, Spain, November 2010

\section{算 Springer}




\section{Editors}

Carmen Andrade

IETcc_CSIC

Madrid, Spain
Giuseppe Mancini

Politecnico di Torino

Italy

ISSN 2211-0844

ISBN 978-94-007-0676-7

e-ISBN 978-94-007-0677-4

DOI 0000000000000

Springer Dordrecht Heidelberg London New York

Library of Congress Control Number: 2011xxxxx

(C) RILEM 2011

No part of this work may be reproduced, stored in a retrieval system, or transmitted in any form or by any means, electronic, mechanical, photocopying, microfilming, recording or otherwise, without written permission from the Publisher, with the exception of any material supplied specifically for the purpose of being entered and executed on a computer system, for exclusive use by the purchaser of the work.

Cover design: eStudio Calamar S.L.

Printed on acid-free paper

Springer is part of Sprincer Science+Business Media (www.springer.com) 


\title{
High Strength Steels Fracture Toughness Variation by the Media
}

\author{
J. Sánchez, J. Fullea and C. Andrade
}

Eduardo Torroja of Construction Science Institute (IETcc-CISDEM-UPM-CSIC), Serrano Galvache, 4, 28033 Madrid, Spain, javiersm@ietcc.csic.es

\begin{abstract}
The stress corrosion cracking process is at this moment an unknown mechanism of deterioration. It is a process that implies the joint action of the media, the presence of corrosion or a surface defect and of stress in the metal. Prestressing tendons can suffer SCC jointly with hydrogen embrittlement which dramatically changes not only the type of fracture (from ductile to brittle) but also the kinetics of the process leading to unexpected collapses. The metal should be resistant to this type of process which can be characterized by its toughness and therefore by its damage tolerance.

This research shows that the Fracture Toughness change when the steel corrodes, questioning the idea that is an intrinsic characteristic of the material. The reduction in the fracture toughness of steel wires when they are in contact to aggressive media involve that the material fractures with a lower crack depth for the same stress level. That means that the material becomes less damage tolerant, which implies that it is necessary to detect defects of smaller size, as for example, small notch, pits or superficial cracks. In the paper some results of the percentage of decrease of the toughness of prestressing wires suffering corrosion are presented.
\end{abstract}

\section{Introduction}

Concrete has an alkaline pore solution $(\mathrm{pH}>12.6)$ that guarantees the passivation of steel reinforcement in addition to be a physical barrier against the penetration of environmental aggressives. This protection can be maintained indefinitely until an aggressive element in enough concentration reaches the bar. The most common causes of corrosion are the carbonation of the concrete cover, which produces a reduction of the $\mathrm{pH}$ of pore solution, and the penetration of chlorides, which induces pitting corrosion. 
A particular case of corrosion of the steel embedded in concrete is the Stress Corrosion Cracking (SCC), which can appear in prestressed structures. The SCC is produced by the simultaneous action and synergy of a mechanical tension and a corrosive media. Nucleated at the steel surface, the result is the appearance of microscopic cracks that are penetrating and inducing the brittle failure of the wire, due to a triaxial stress condition.

The Fracture Toughness $\left(\mathrm{K}_{\mathrm{IC}}\right)$ is one of the most important parameters in Fracture Mechanics. Prestressed wires present high fracture toughness and, until now, this parameter has been considered as a characteristic of the materials. The fracture toughness is one of the fracture criteria [1]. This parameter is based on the knowledge of the stress ranges and displacement in the surroundings of the crack, that is to say, is based on the Stress Intensity Factor $\left(\mathrm{K}_{\mathrm{I}}\right)$. Therefore, the fracture takes place when the stress intensity factor reaches the limit condition: $\mathrm{K}_{\mathrm{I}}=\mathrm{K}_{\mathrm{IC}}$.

There are a standard to measure the fracture toughness: ASTM E 399-90 (1997): "Standard Test for Method Plane-Strain Fracture Toughness of Metallic Materials". This standard provides details on the geometry of the specimens (Single Edge, Compact, Arc, etc.) and the minimum thickness based on the fracture toughness of the material and its elastic limit. This indicates that the fracture toughness varies with the thickness, decreases as increases the thickness until reaching a constant value from a big thickness. In addition, the fracture toughness depends on the rate of the test and the temperature.

The present work shows that the Fracture Toughness $\left(\mathrm{K}_{\mathrm{IC}}\right)$ of steel varies when it remains in the media susceptible to the corrosion. That is to say, during the process of Stress Corrosion Cracking (SCC) the fracture toughness diminishes. Until now, the fracture toughness has been considered like a constant of the material. The reduction in the fracture toughness implies that the material, for a same tensional level, fractures with a defect much smaller. That is to say, the material becomes less tolerant to the damage, which implies that it is necessary to detect defects, like for example, small notches, superficial pits or cracks.

In order to support this statement it is shown some SCC results of high strength steel in carbonated solutions. In these tests, instead of generating the crack by fatigue, it is generated by means of controlled electrochemical and mechanical conditions. After that, it is possible to estimate the fracture toughness in a simple test. The obtained results show decreases around $30-40 \%$ of the fracture toughness with respect to the fatigue method value. 


\section{Experimental Method}

\section{Materials}

A steel of eutectic composition have been tested in two conditions: cold drawn steel (1510 MPa Yield Strength) and the modified parent pearlitic steel (1300 MPa Yield Strength). The chemical composition of both is therefore the same and it is shown in Table I:

Table I. Chemical composition of parent pearlitic steel (\%w)

\begin{tabular}{lllllll}
\hline $\mathrm{C}$ & $\mathrm{Si}$ & $\mathrm{Mn}$ & $\mathrm{P}$ & $\mathrm{Cr}$ & $\mathrm{Ni}$ & $\mathrm{S}$ \\
0.8 & 0.2 & 0.7 & $\leq 0.02$ & 0.20 & 0.074 & $\leq 0.03$ \\
\hline
\end{tabular}

Parent pearlitic steel has treated thermally to a temperature about $250{ }^{\circ} \mathrm{C}$ during 15 minutes [2-3]. The purpose of this treatment is to increase the yield strength from $950 \mathrm{MPa}$ of the raw material to $1273 \mathrm{MPa}$. The value of the fracture toughness for this material is $\mathrm{K}_{\mathrm{IC}}=58 \mathrm{MPa} \mathrm{m}^{0.5}$ [2]. And, the fracture toughness value for cold drawn steel is $107.9 \mathrm{MPa} \mathrm{m}^{0.5}$ [4].

The samples were mechanized to a diameter of $2.5 \mathrm{~mm}$ and a length of $13.2 \mathrm{~mm}$. In this case it is not possible to obtain standardized geometries, and then it is necessary to test cylindrical samples.

\section{Methodology}

A set of tests were carried out to localize the generation of single pit and avoid depassivation in the rest of the surface. The more realistic conditions are based in the generation of a crack by electrochemical dissolution from a pit [3,5-6], which may represent better the reality than to generate the crack by fatigue. After several trials, epoxy coating was used in order to avoid depassivation by generation of various pits. A notch artificially made to leave the steel surface in contact with the solution was used to reproduce a single pit.

In the test method the mechanical and electrochemical parameters are combined and it is made up of the following stages:

1. Fixed potential test in the media: The specimen is immersed in a solution of sodium bicarbonate at constant temperature. A fixed potential is applied, during around 100 hours, simultaneously a data logger registers the current. The specimen is strained to $80 \%$ of its yield strength. The objective of this stage is to generate an anodic zone and control the crack growth. After this stage, the specimens are removed from the solution and dried.

2. Slow strain rate test in air: SSRT is performed in air at a rate of $3 * 10^{-7} \mathrm{~s}^{-1}$ in order to determine the fracture toughness. It is possible to obtain the fracture 
toughness using the fracture mechanics calculations from the stress and crack size data.

3. Scanning Electron Microscope analysis (SEM): In order to examine the fracture surface is used a scanning electron microscope. From this fractographic analysis is possible to evaluate the size of the crack in the fracture surface and the existence or not of brittle zones. In addition it is possible to determine the reduction of area, the different zones of surface of fracture and formed oxides.

\section{Results}

Once selected the right method of concentration of the damage [3, 6], some tests were carried out in order to know the influence of the applied potential on the crack propagation at constant load. The potential resulting more sensitive to induce $\mathrm{SCC}$ is $-275 \mathrm{mV}_{\mathrm{Ag} / \mathrm{AgCl}}$ in the used bicarbonate solution.

Figure 1 shows two different behaviours. It is possible to see an example of a test for a material without defects and it is shown the curve corresponding to a material that has a crack generated in bicarbonate solution. The fracture for first is completely ductile (Figure 2) with the formation of micro-voids, whereas for the second case is completely brittle (Figure 3a). This type of fracture is characterized by a small area reduction and the fracture takes place in the same plane of the crack. This mechanical fracture is characterized by the appearance of brittle zones called cleavage (Figure $3 b$ ).

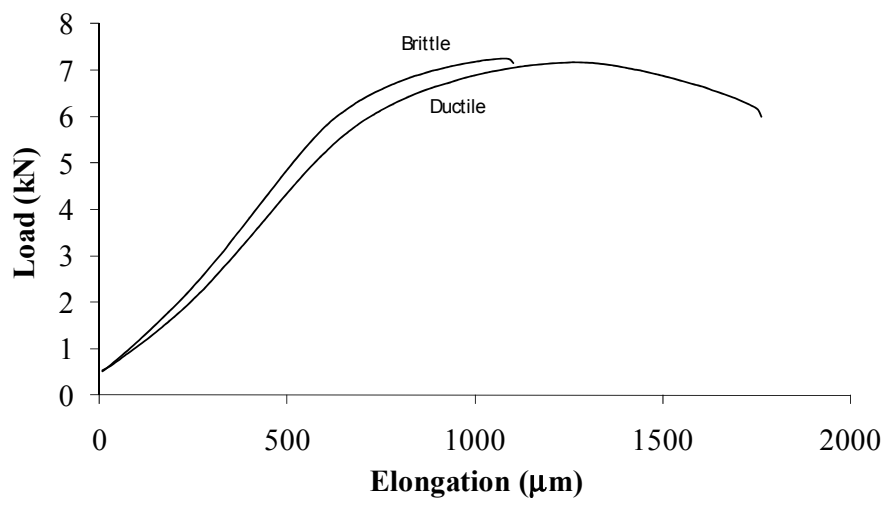

Figure 1. Ductile behaviour versus brittle behaviour 

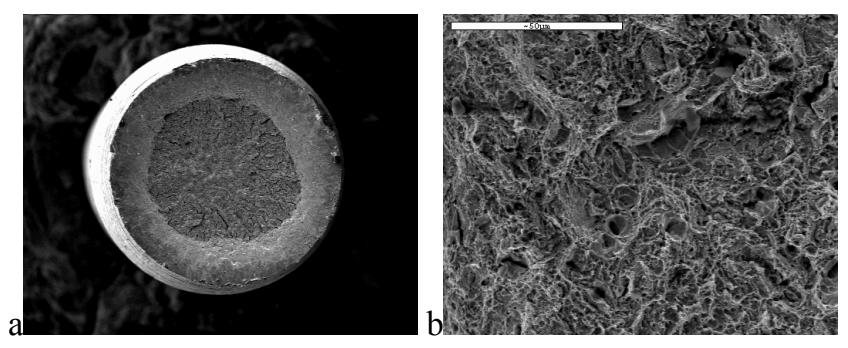

Figure 2. Ductile surface of fracture: a) general view, b) micro-voids
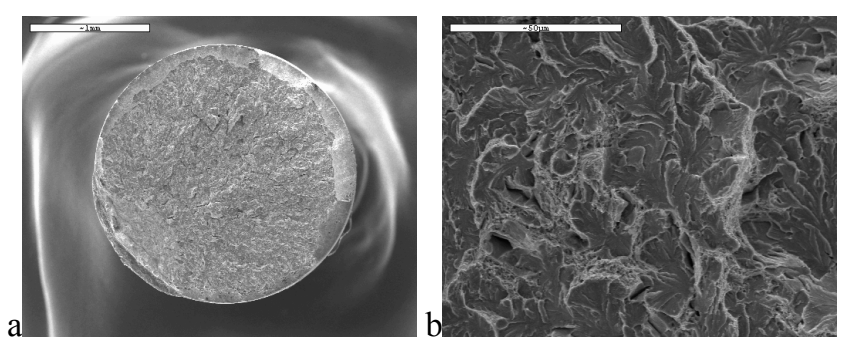

Figure 3. Brittle surface of fracture: a) general view, b) cleavage detail

\section{Discussion}

Due to limited size of the samples, prestressed steels cannot be prepared to obtain standardized specimens for testing fracture toughness of the material (ASTM E399-78) and therefore other approaches are necessary. For the case of a cylindrical geometry of the material, the calculation of the stress intensity factor and the criterion of fracture can be calculated through Astiz, Valiente and Elices's equation [1,7] or through Levan and Royer's equation [8]. The above mentioned authors have assumed that cracks along the whole perimeter of the specimen are formed and the superficial cracks have semi-ellipse shape (Figure 4). Equations 1 and 2 give the expression corresponding to the stress intensity factor for a superficial crack with semi-elliptical form according Astiz and Levan's work.

$$
\begin{aligned}
& \frac{K_{I}}{\sigma \sqrt{\pi a}}=\sum_{i} \sum_{j} C_{i j}\left(\frac{a}{2 R}\right)^{i}\left(\frac{a}{b}\right)^{j} \\
& \frac{K_{I}}{\sigma \sqrt{\pi a}}=\sum_{i} \sum_{j} \sum_{k} C_{i j k}\left(\frac{a}{R}\right)^{i} a^{j}\left(\frac{s}{s m}\right)^{k}
\end{aligned}
$$



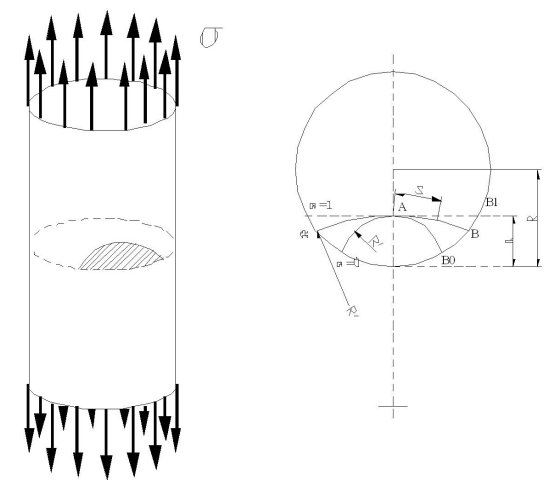

Figure 4. Superficial crack in a wire

However, the two previous equations have two main limitations to be applied in this study. Firstly, both are only applicable to linear elastic materials. And secondly, the geometry of the crack obtained by stress corrosion cracking must be for form factors $=\mathrm{a} / \mathrm{R}$ ratios smaller than about 0.5 which is smaller than those observed in our experimentation $[3,6]$.

Both equations are represented in Figure 5. Until a depth of cracks an around 0.5 times the radius $\mathrm{R}$, it is observed quite good accordance between the predictions of both equations. It is worth noting that, for greater depths of crack, as it is the case of those observed by us in prestressing wires, the value of stress intensity factor calculated from the equation of Levan [8] is much higher than that one calculated by the equation of Astiz [7].

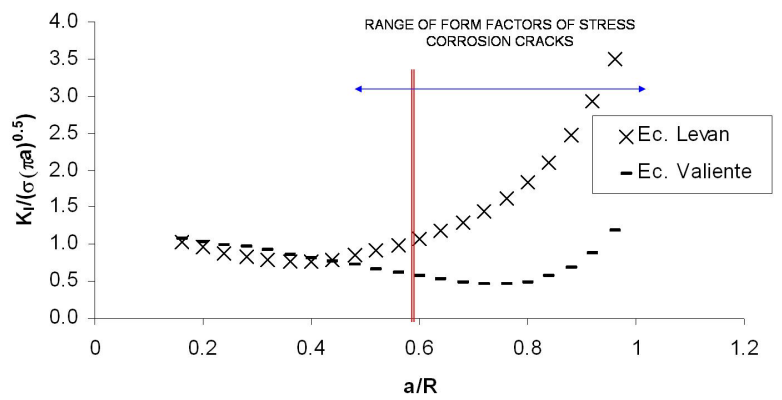

Figure 5. Comparison stress intensity form factors for specimens of cylindrical shape according Astiz and Levan et al.

For so acute cracks in cylindrical specimens it has not been found a rupture criterion that allows considering in a simple manner. Then, present paper shows previous calculations about Stress Intensity Factor for a bar with a crack geometry 
similar to that generated by stress corrosion, from solving the Integral J obtained by Finite Element calculation [9].

Results are given next for the different simulated crack sizes, always for the same value of semi-axis $b$ and the same characteristics of the material, those corresponding to the steel of 6 sinking passages and to those of the parent steel. The crack length "a" varies between $200 \mu \mathrm{m}$ and $1200 \mu \mathrm{m}$. Figure 6 shows the values of the Integral $\mathrm{J}$ for the cold drawn steel calculated in function of the stress. An abrupt change in the slope for the load level is observed where the plastic deformation of the surface of fracture begins. The same happens for parent steel (Figure 7). Once the values of the Integral $J$ are obtained for each crack size, the stress intensity factor can be estimated according Irwin equation [10]. Figures 8 and 9 depict the values of KI so calculated, for the Cold drawn and Parent steels.

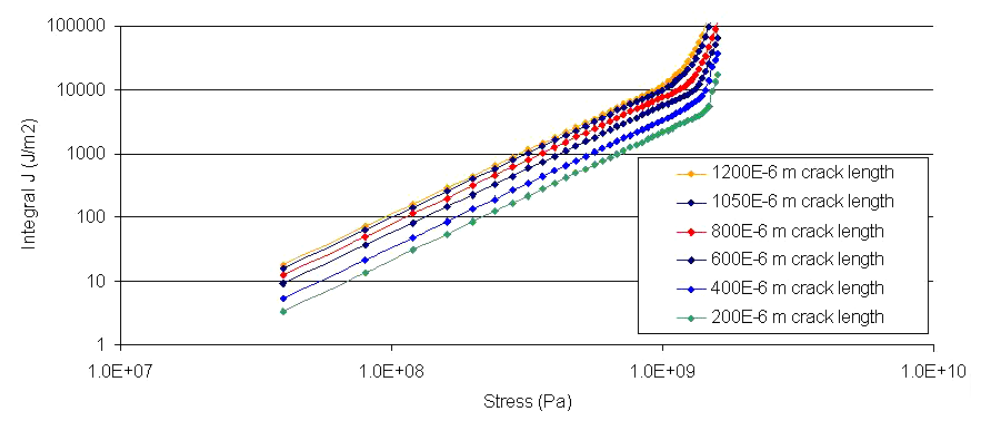

Figure 6. Integral J calculated for cold drawn steel in function of the stress

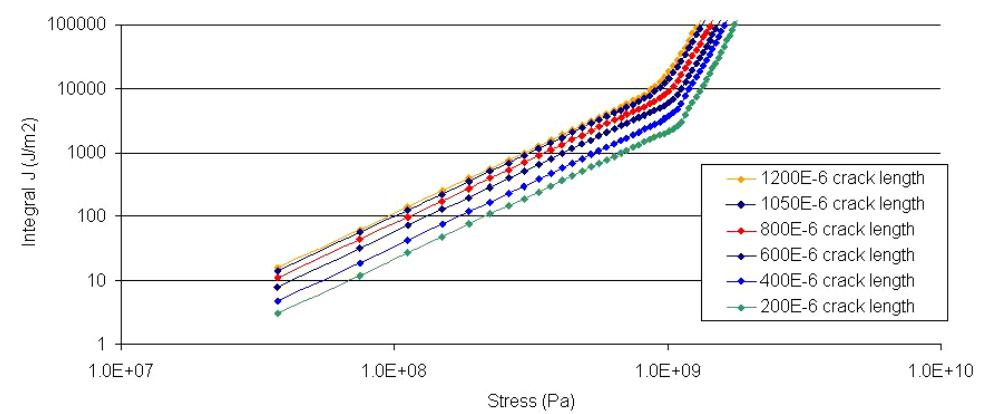

Figure 7. Integral J calculated for parent pearlitic steel in function of the stress 


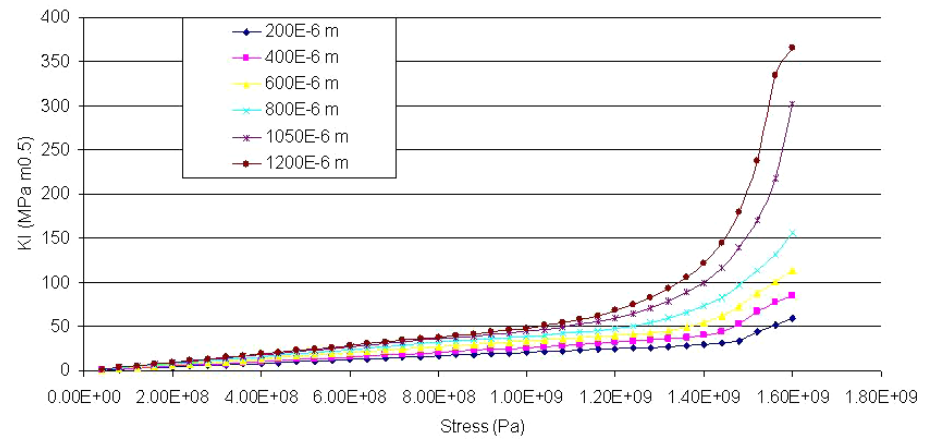

Figure 8. Values of $\mathrm{K}_{\mathrm{I}}$ for the Cold drawn steel calculated from the Integral J

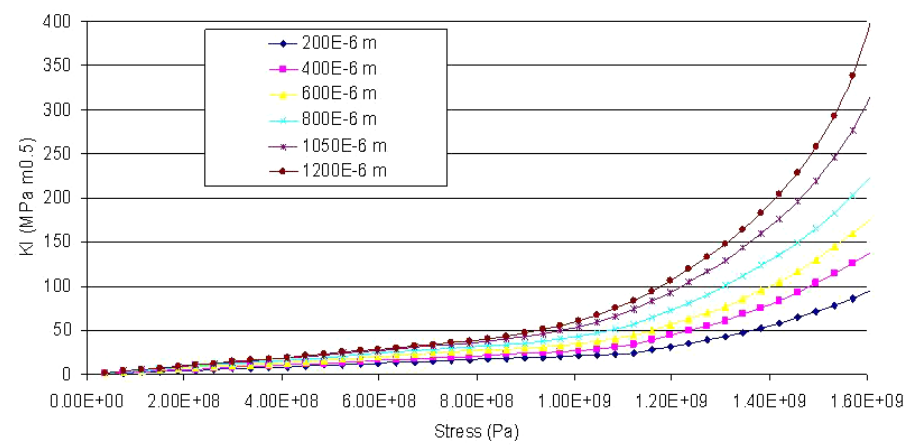

Figure 9. Values of $\mathrm{K}_{\mathrm{I}}$ for the Parent steel calculated from the Integral J

As made in to previous studies $[3,5,6]$ it is possible to calculate the fracture toughness of high strength steels from the crack geometry and the fracture parameters as shown in Figure 3 and according previously defined methodology. Figures 10 and 11 show the values of the fracture toughness for cold drawn and parent steel. The fracture toughness of the cold drawn steel is higher than parent steel one, although it can be distinguished a large variation of the fracture toughness in both materials. In all cases it is achieved very smaller values, around 50 MPam 0.5 or less than the nominal ones. This means that the damage tolerance is reduced dramatically by the media, because when the crack grows up by stress corrosion cracking, the fracture toughness can be reduced around $40 \%$ by the hydrogen effect [11-13]. This reduction indicates the need to reconsider the crack depth needed to develop a brittle failure in the case of corroding high strength steels and therefore, to reduce the expected damage tolerance of these steels when they develop cracks by stress corrosion. 


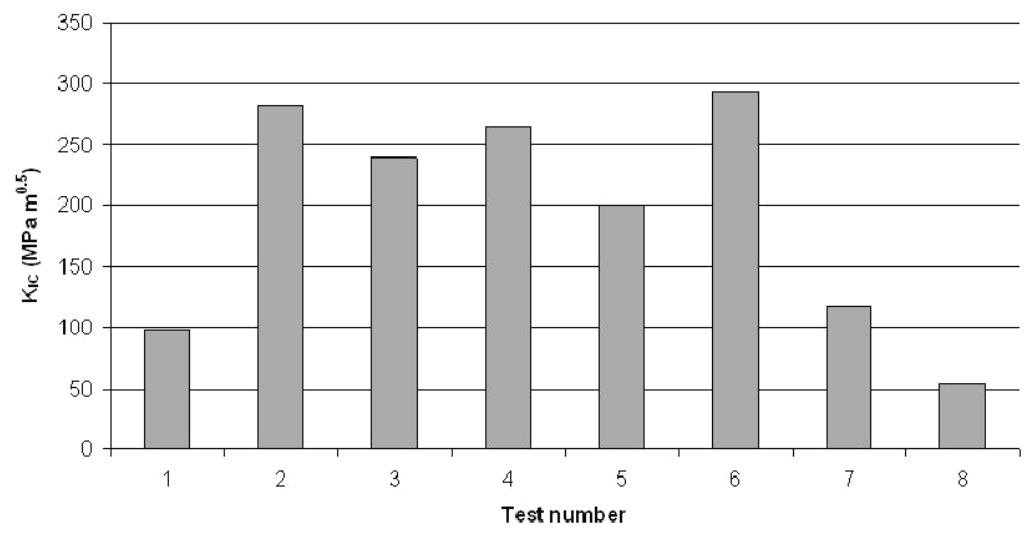

Figure 10. Fracture toughness of cold drawn steel before SCC test

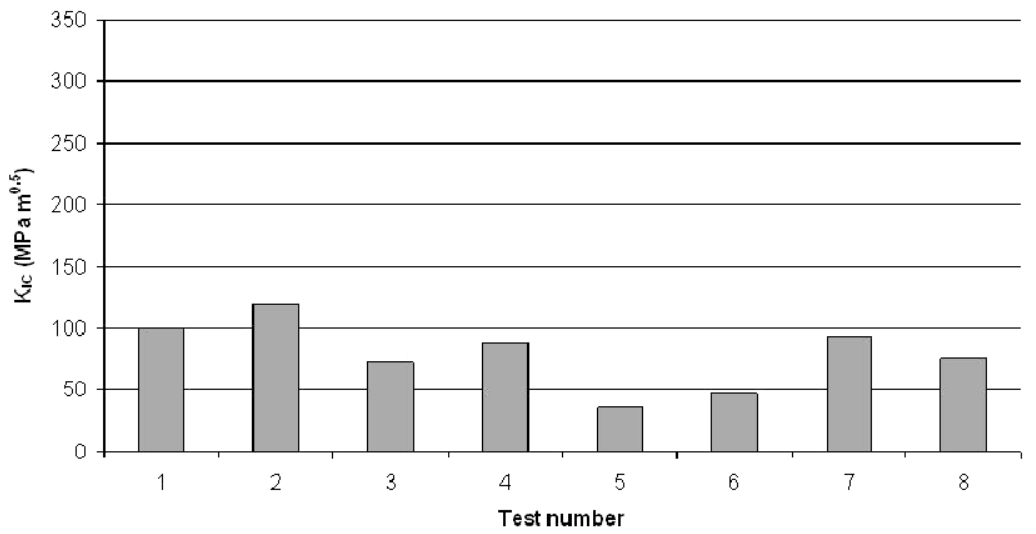

Figure 11. Fracture toughness of parent steel before SCC test

\section{Conclusions}

The fracture toughness of metals has been considered a material characteristic with fixed values that are normally determined by means of fatigue tests. Present results obtained from steels specimens coated with epoxy resin, were the crack is induced by corrosion on a notch made in the coating, have indicated that the toughness is significantly reduced when the material is immersed in media inducing stress corrosion cracking processes. Although these tests should be extended to other media in order to know how much this conclusion regarding prestressing steels, it is an indication of a need to review the damage tolerance of prestressed structures in some contaminated atmospheres. 


\section{Acknowledgments}

The authors wish to thank Ministerio de Fomento of Spain for the funding the accomplishment of the project "Not destructive methods and strategies for the control of the corrosion in pretested steels", the INGENIO 2010-CONSOLIDER Project on "Safety and Durability of Structures: SEDUREC" and, specially, to Prof. Gustavo Guinea (UPM).

\section{References}

[1] Valiente A., Elices M. (1998), Eng. Fail. Anal. 5, 219.

[2] Parkins R. N., Elices M., Sanchez-Galvez V., Caballero L. (1982), Corrosion Science 22, 379.

[3] Sanchez J., Fullea J., Andrade C., Alonso C. (2007), Corrosion Science 49, 4069.

[4] Toribio J. (2004), Materials Science and Engineering a-Structural Materials Properties Microstructure and Processing 387, 227.

[5] Sanchez J., Andrade C., Fullea J. (2009), Corrosion 65, 368.

[6] Sanchez J. (2007), PhD Thesis. Complutense of Madrid.

[7] Astiz M. A. (1986), International Journal of Fracture 31, 105.

[8] Levan A., Royer J. (1993), International Journal of Fracture 61, 71.

[9] ABAQUS (2005).

[10] Irwin G. R. (1957), Journal of Applied Mechanics 24, 361.

[11] Sanchez J., Fullea J., Andrade C., de Andres P. L. (2010), Physical Review B 81, 132102.

[12] Sanchez J., Fullea J., Andrade C., de Andres P. L. (2009) Diffusion in Materials - Dimat2008 289-292, 203.

[13] Sanchez J., Fullea J., Andrade C., de Andres P. L. (2008) Physical Review B 78, 014113. 